\title{
Late Presentation of a Congenital Intrinsic Duodenal Obstruction in a Patient with Anorectal Malformation
}

\author{
Parkash Mandhan $^{1^{*}}$, Kirtikumar J. Rathod ${ }^{1}$, Dilip Sankhla ${ }^{2}$ \\ ${ }^{1}$ Division of Paediatric Surgery, Department of Surgery, Sultan Qaboos University Hospital, Muscat, Oman \\ ${ }^{2}$ Department of Radiology, Sultan Qaboos University Hospital, Muscat, Oman \\ Email: *kidscisurg@ilcoud.com
}

Received February $8^{\text {th }}, 2013$; revised March $11^{\text {th }}, 2013$; accepted March $20^{\text {th }}, 2013$

Copyright (C) 2013 Parkash Mandhan et al. This is an open access article distributed under the Creative Commons Attribution License, which permits unrestricted use, distribution, and reproduction in any medium, provided the original work is properly cited.

\begin{abstract}
Anorectal Malformations are known to be associated with various other congenital anomalies including duodenal atresia. An association of congenital intrinsic duodenal obstruction causing partial duodenal obstruction in a patient with anorectal malformation is not described in literature. We describe a case of delayed presentation of congenital intrinsic duodenal obstruction in a child with high-type anorectal malformations causing diagnostic dilemma.
\end{abstract}

Keywords: Anorectal Malformations; Duodenal Obstruction; VACTERL Association; Delayed Presentation; Infant

\section{Introduction}

The association of duodenal obstruction is described in about $1 \%-2 \%$ of patients with Anorectal Malformations (ARMs) [1]. The cases described in the literature are of duodenal atresia (complete duodenal obstruction) where anomalies are diagnosed much early in the life [2-4]. Delayed presentation of duodenal obstruction due to congenital intrinsic duodenal obstruction (CIDO) has been described [5-7], but to the best of our knowledge, this associated with ARMs has not been reported yet. We present an infant who was born with high-type ARM and presented to us at 10 months of age with symptoms of incomplete duodenal obstruction due to CIDO after completing all the stages of high type ARM surgery elsewhere.

\section{Case Report}

A 10-month-old male infant presented to pediatric emergency department with history of recurrent vomiting and failure to thrive. His height and weight was below third percentile for his age. He also had multiple hospitalizations for his recurrent vomiting and till today was able to tolerate only liquids in between these episodes. On examination, he was mildly dehydrated and his upper abdomen was full and soft. His perineal examination revealed an anal opening of adequate in size and shape with good

*Corresponding author. muscle complex. He also had bilateral palpable undescended testis. The records of previous hospitalizations and surgeries revealed that he was born with high-type ARM and had sigmoid colostomy in neonatal period followed by laparoscopic assisted anorectoplasty at 6months of age and later reversal of stoma. He had mild hydrocephalus (arrested) with no spinal malformations.

After assessment and stabilization, his plain X-ray abdomen revealed dilated stomach and duodenum with minimal air in the proximal bowel loops suggesting incomplete bowel obstruction. His upper gastrointestinal (GI) contrast study showed grossly distended stomach and $2^{\text {nd }}$ part of duodenum and delayed passage of contrast from duodenum to jejunum (Figure 1) suggestive of CIDO. He was explored and laparotomy showed dilated stomach and $2^{\text {nd }}$ part of duodenum and a narrow duodenum downward with some air and fluid in the proximal small bowel loops. A duodenotomy in the dilalted duodenum revealed a diaphragm with a hole allowing passage of a small probe down into distal duodenum. A diamond shaped duodenostomy was performed for his CIDO. He tolerated procedure very well and was discharged home when he tolerated adequate oral feeds. He presented few weeks later with features of intestinal obstruction, which was confirmed by radiological images. He required another laparotomy, which revealed multiple soft adhesions causing small bowel obstruction, which were released by adhesiolysis. His 
post-operative course was smooth and he was discharged in good health and tolerating adequate solid feeds. His Upper GI contrast study after 3-monthsof last surgery showed free passage of contrast along the whole length of bowel with no evidence of obstruction (Figure 2). He was also evaluated for VACTERL association and noted to have associated renal anomalies (single kidney). He had elective bilateral orchidopexyat age of 18-months. During his serial follow-ups in a multidisciplinary clinic for last 30 months, he has remained asymptomatic with good growth and development according to his age.

\section{Discussion}

Children born with ARMs are known to have associated anomalies of other systems [2,8]. The rare association of ARMs with duodenal atresia has also been known [9], but the association of ARMs with incomplete duodenal obstruction, as in our case, has not been reported yet and this is a first case report of mentioned multiple malformations.

Children born with CIDO have been reported to have a high incidence of Down syndrome (trisomy 21) and congenital heart defects [10]. Smith et al. reported four children presenting in late childhood with features of duodenal obstruction, but all had associated Down syndrome [11]. Similarly, case reported by Lee et al., who presented at age of 3-year with recurrent episodes of vomiting, and diagnosed as a case of congenital duodenal stenosis also had associated Down syndrome [12]. However, in our case, there was no association of trisomy 21 as well as congenital cardiac defects. On the contrary, he had associated renal anomalies (single kidney) and bilateral undescended testis, which are also known to be associated with ARMs i.e. VACTERL (Vertebral, Anal, Cardiac, Tracheoesphageal, Renal and Limb) association. Studies done in animals [13] and humans [14] have shown that shh and its targets BMP4 and posterior Hox genes play a pivotal role in development of hindgut. Rathod et al. have reported a novel association of foregut and hindgut anomalies (duodenal atresia, ARMs, intestinal malrotation and esophageal atresia) in single patient [15]. Does shh and its targets have an extended role in the development of duodenum, yet needs to be further explored.

The late presentation of CIDO in our case after finishing all the stages of ARM repair including laparoscopic guided pull-through raises the concern of difficulty in dia-

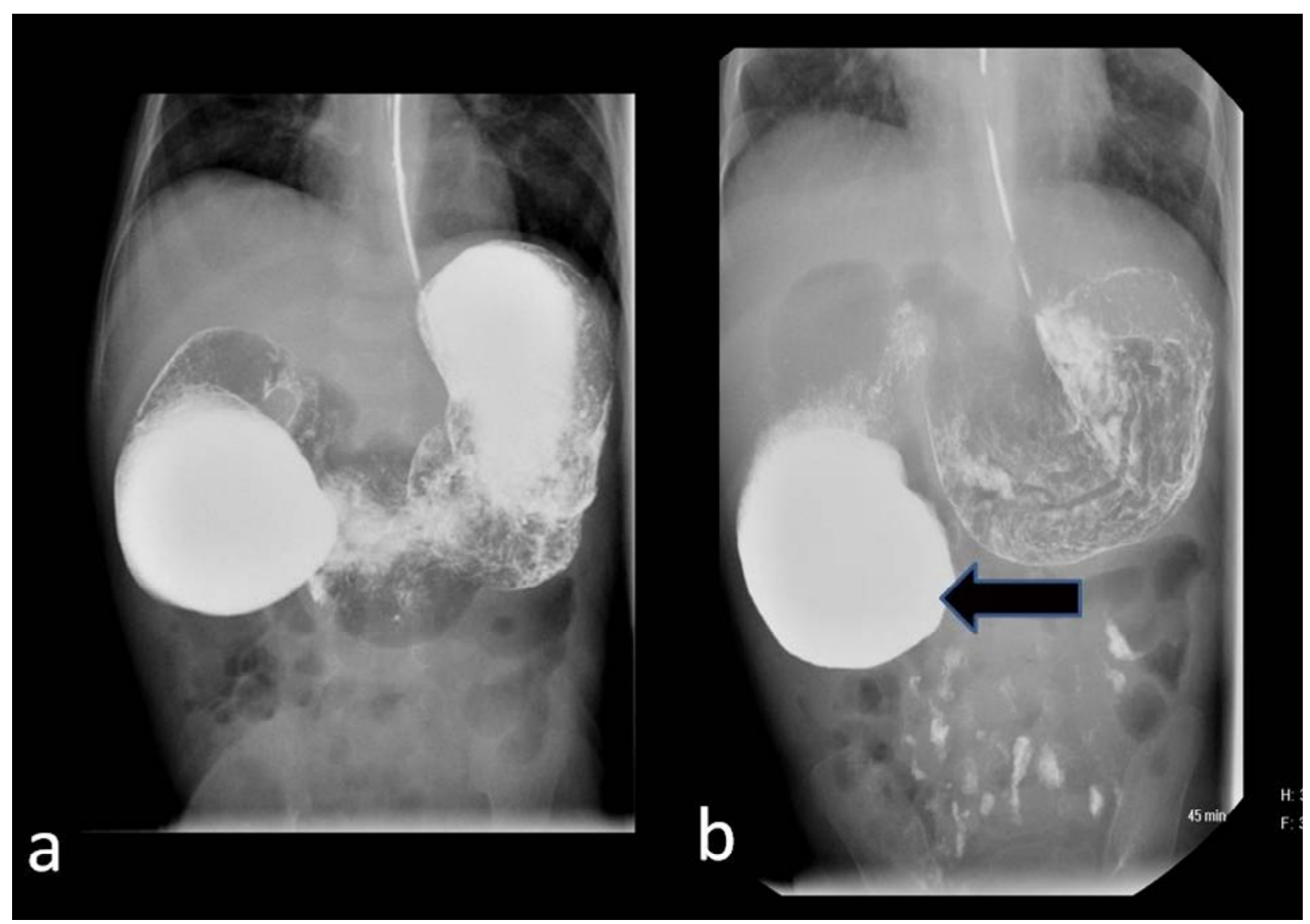

Figure 1. Preoperative upper gastrointestinal contrast study showing distended stomach and proximal duodenum: (a) Note the delayed passage of minimal amount of oral contrast in the distal small bowel; (b) Features suggestive of congenital intrinsic duodenal obstruction (dilated $2^{\text {nd }}$ part of duodenum - thick black arrow). 


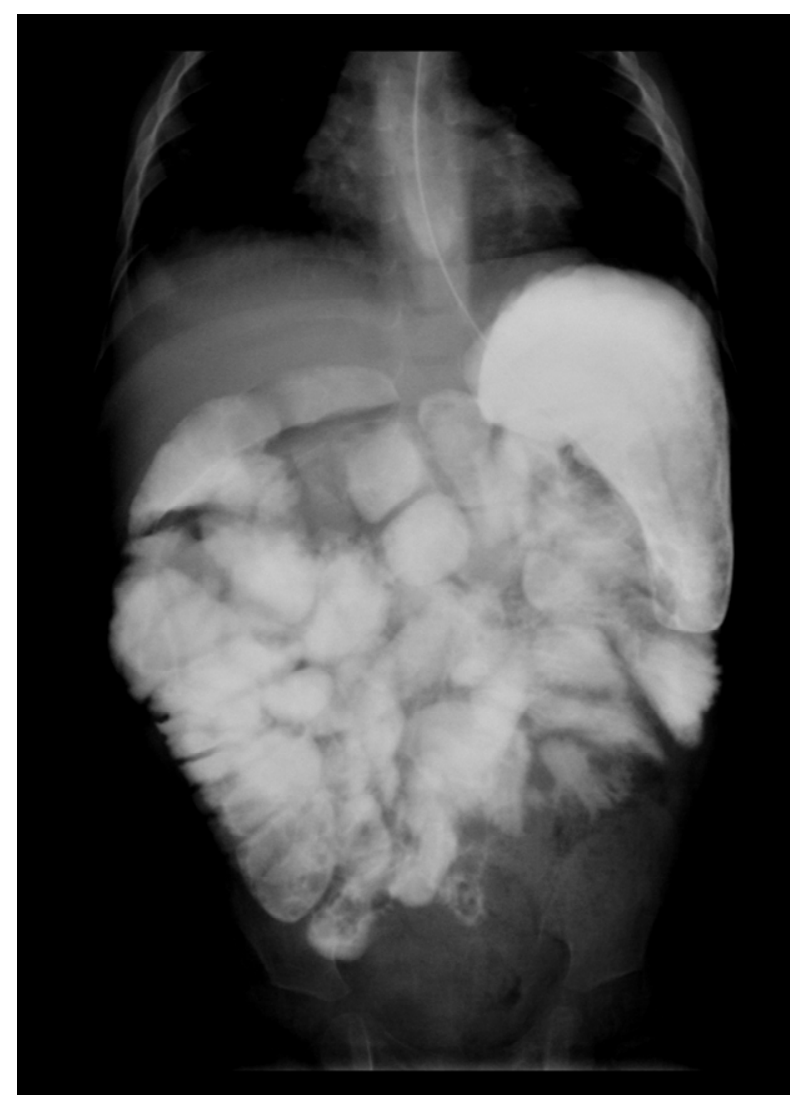

Figure 2. Postoperative contrast study (after 3-mouth of surgery) showing free passage of oral contrast across the duodenum and uniformly distended small bowel loops.

gnosis of CIDO in absence of Down syndrome. It implies the importance of further evaluation for unrecognized associated anomalies. Also it signifies the extended value of minimal invasive surgery in children to perform a thorough inspection of abdomen in presence of symptoms unrelated to known cause or previous surgical procedures.

In summary, infants with multiple congenital anomalies may not present with classical findings in the first few days of life. A high index of suspicion and careful systemic evaluation in relation to the symptoms is highly recommended in children with complex malformations to avoid the diagnosis of missing anomalies and also to choose the optimal early surgical intervention.

\section{REFERENCES}

[1] A. Pena and M. Levitt, “Anorectal Malformations,” In: J. L. Grosfeld, J. A. O’Neil, E. W. Fonkalsrud, et al., Eds., Text Book of Pediatric Surgery, Mosby Elsevier, Philadelphia, 2006, pp. 1566-1589.

[2] E. A. Hassink, P. N. Rieu, B. C. Hamel, et al., "Additional Congenital Defects in Anorectal Malformations," European Journal of Pediatrics, Vol. 155, No. 6, 1996, pp. 477-482. doi:10.1007/BF01955185

[3] N. Morikawa, T. Kuroda, T. Honna, et al., “A Novel
Association of Duodenal Atresia, Malrotation, Segmental Dilatation of the Colon, and Anorectal Malformation," Pediatric Surgery International, Vol. 25, No. 11, 2009, pp. 1003-1005. doi:10.1007/s00383-009-2459-y

[4] C. Stoll, Y. Alembik, B. Dott, et al., "Associated Malformations in Patients with Anorectal Anomalies," European Journal of Medical Genetics, Vol. 50, No. 4, 2007, pp. 281-290. doi:10.1016/j.ejmg.2007.04.002

[5] A. Beeks, J. Gosche, H. Giles, et al., "Endoscopic Dilation and Partial Resection of a Duodenal Web in an Infant,” Journal of Pediatric Gastroenterology \& Nutrition, Vol. 48, No. 3, 2009, pp. 378-381. doi:10.1097/MPG.0b013e31818c600f

[6] A. Y. Kshirsagar, S. R. Sulhyan, G. Vasisth, et al., "Duodenal Stenosis in a Child," African Journal of Paediatric Surgery, Vol. 8, No. 1, 2011, pp. 92-94. doi:10.4103/0189-6725.78940

[7] M. G. Peetsold, S. Ekkelkamp and H. A. Heij, "Late Presentation of a Duodenal Web in a Patient with Situs Inversus and Apple Peel Jejunal Atresia,” Pediatric Surgery International, Vol. 20, No. 4, 2004, pp. 301-303. doi:10.1007/s00383-003-1132-0

[8] G. R. Boocock and D. Donnai, "Anorectal Malformation: Familial Aspects and Associated Anomalies," Archives of Disease in Childhood, Vol. 62, No. 6, 1987, pp. 576-579. doi:10.1136/adc.62.6.576

[9] M. M. Harjai, "Congenital Triple Atresia of the Esophagus, Duodenum and Rectum-A Diagnostic Dilemma," Medical Journal Armed Forces India, Vol. 56, No. 4, 2000, pp. 334-335.

[10] R. Niramis, M. Anuntkosol, A. Tongsin, et al., "Influence of Down's Syndrome on Management and Outcome of Patients with Congenital Intrinsic Duodenal Obstruction," Journal of Pediatric Surgery, Vol. 45, No. 7, 2010, pp. 1467-1472. doi:10.1016/j.jpedsurg.2010.02.049

[11] G. V. Smith and R. L. Teele, "Delayed Diagnosis of Duodenal Obstruction in Down Syndrome," American Journal of Roentgenology, Vol. 134, No. 5, 1980, pp. 937-940. doi:10.2214/ajr.134.5.937

[12] S. S. Lee, S. T. Hwang, N. G. Jang, et al., "A Case of Congenital Duodenal Web Causing Duodenal Stenosis in a Down Syndrome Child: Endoscopic Resection with an Insulated-Tip Knife,” Gut and Liver, Vol. 5, No. 1, 2011, pp. 105-109. doi:10.5009/gnl.2011.5.1.105

[13] P. Mandhan, Q. B. Quan, S. Beasley, et al., "Sonic Hedgehog, BMP4, and Hox Genes in the Development of Anorectal Malformations in Ethylenethiourea-Exposed Fetal Rats,” Journal of Pediatric Surgery, Vol. 41, No. 12, 2006, pp. 2041-2045. doi:10.1016/j.jpedsurg.2006.08.035

[14] J. Zhang, Z. B. Zhang, H. Gao, et al., "Down-Regulation of SHH/BMP4 Signalling in Human Anorectal Malformations," Journal of International Medical Research, Vol. 37, No. 6, 2009, pp. 1842-1850. doi:10.1177/147323000903700620

[15] K. J. Rathod, D. Vaze and K. L. Narasimhan, "Novel Association of Multiple Gastrointestinal Anomalies in a Single Patient: Can Sonic Hedgehog Explain It?” Congenital Anomalies (Kyoto), Vol. 52, No. 1, 2012, pp. 62 63. doi:10.1111/j.1741-4520.2011.00320.x 